\title{
Salvage Cryotherapy for Radiation-Recurrent Prostate Cancer: Outcomes and Complications
}

\author{
David S. Finley • Arie S. Belldegrun
}

Published online: 11 March 2011

(C) The Author(s) 2011. This article is published with open access at Springerlink.com

\begin{abstract}
Potentially curative salvage options for radiorecurrent prostate cancer include prostatectomy, brachytherapy, high-intensity focused ultrasound, and cryotherapy. Salvage cryoablation technology, surgical technique, oncologic outcomes, and complication rates have improved dramatically over the past few decades, shifting this treatment modality from investigational status to an established therapeutic option. In this review, we focus on the most up-to-date oncologic and functional outcomes, as well as complications of salvage cryotherapy for radiationrecurrent prostate cancer.
\end{abstract}

Keywords Cryoablation - Ablative therapy - Salvage . Failure $\cdot$ Radiation $\cdot$ Prostate cancer $\cdot$ Recurrence . Complications

\section{Introduction}

In the United States alone, about one third of the 200,000 men who are diagnosed with prostate cancer each year will undergo primary radiotherapy (RT) with external beam or brachytherapy $[1,2]$. Failure rates vary according to the failure definition, RT modality and dose, duration of follow-up time, and clinicopathologic characteristics, but generally average $30 \%-40 \%$ (range: $10 \%-40 \%$ ) [3-7]. After RT for prostate cancer, it has been demonstrated that up to one third of patients with biochemical failure will have a positive biopsy [8]. Currently, there are four

\footnotetext{
D. S. Finley $(\triangle) \cdot$ A. S. Belldegrun

Institute of Urologic Oncology,

David Geffen School of Medicine at UCLA,

924 Westwood Boulevard, Suite 1050, Box 957207,

Los Angeles 90095-7207 CA, USA

e-mail: dfinley@mednet.ucla.edu
}

salvage options with curative intent: radical prostatectomy, brachytherapy, high-intensity focused ultrasound, and cryoablation. Each treatment choice has varying oncologic outcomes, side-effect profiles, and complication rates. Relative to the most aggressive and definitive approach of salvage prostatectomy, cryoablation seeks to strike a balance between cancer control and toxicity.

First-generation cryosurgical systems in the 1960s utilized liquid nitrogen to create an ice ball, which suffered from imprecise control and monitoring, resulting in a high complication rate. Today's third-generation cryounits have transitioned to argon/helium-based systems according to the Joule-Thompson principle to create precisely controlled isotherms through ultrathin needles. Ultrasound imaging has coevolved with cryotechnology, now incorporating the routine use of multitemperature sensing probes, double freeze-thaw cycles, and urethral warming catheters. Taken together, these revolutionary technical advances along with improvements in technique have led to dramatic reductions in toxicity and more favorable outcomes.

\section{Patient Selection}

Cryotherapy has been used for primary whole gland and focal treatment, salvage whole gland and focal ablation, and local recurrence after radical prostatectomy [9]. While there are no standardized criteria for the selection of patients for salvage cryotherapy, treatment is generally recommended for men with a rising prostate-specific antigen (PSA) after RT who have a positive prostate biopsy and negative metastatic work-up $[10,11]$. According to the 2008 American Urological Association (AUA) Best Practice Consensus Statement, ideal candidates for salvage cryoablation also should have absence of seminal vesicle 
invasion, a PSA less than $10 \mathrm{ng} / \mathrm{mL}$ (preferably $<4 \mathrm{ng} / \mathrm{mL}$ ), a PSA doubling time of 16 months or more, and at least a 10 -year life expectancy $[12 \bullet, 13,14]$. Because up to $30 \%$ of high-risk patients may harbor micrometastatic disease to the lymph nodes, a lymph node dissection may be indicated [12•]. Other factors such as gland volume larger than 50 to $60 \mathrm{~cm}^{3}$ or prior transurethral resection may exclude patients in some cases [12•]. Although a history of brachytherapy may complicate needle placement, it is generally not considered to be a contraindication to salvage cryosurgical ablation.

\section{Oncologic Outcomes}

A rim of PSA-producing periurethral tissue will invariably remain after salvage cryoablation. As a result of these remnant cells, a zero PSA (ie, undetectable) is unlikely to be achieved, and therefore, a post-treatment biopsy may be the most definitive determination of treatment failure after salvage cryoablation. Although some authors have suggested a biopsy for patients with various post-salvage cryotherapy PSA values or in the setting of a persistently increasing PSA, we recommend routine biopsy in every patient (Table 1). However, this practice is unpopular with patients, has potential complications, and is subject to sampling error [15]. Thus, at most institutions, this is not a per protocol routine. Among the few series that have engaged in this practice, positive biopsy rates after salvage cryoablation have ranged from $0 \%$ to $37 \%$ (Table 1). Among one of the largest series, Chin and colleagues [16•] biopsied more than $95 \%$ of patients $(n=178)$, detecting cancer in $16.7 \%$ of biopsies.

Absent biopsy information, no standardized definition of treatment success or failure has been established. Instead, a variety of PSA-based definitions of failure have been adopted from radiation oncologists as a surrogate for treatment efficacy. Whether or not a definition based on radiobiology instead of cryobiology is valid remains to be determined with any certainty. The AUA Best Practice Statement indicated that the presence of persistent disease on biopsy or a PSA value less than $0.5 \mathrm{ng} / \mathrm{mL}$ are commonly used outcome end points. Perhaps the most widely used definitions of failure are: 1) the American Society for Therapeutic Radiology and Oncology (ASTRO) definition: three consecutive increases after the nadir PSA level; 2) the Phoenix definition: PSA nadir after RT $+2 \mathrm{ng} / \mathrm{mL}$; and, 3) PSA of 2 or higher above post-salvage cryotherapy nadir. Previously identified pretreatment prognostic variables that correlate with salvage cryotherapy failure include serum PSA level of above $10 \mathrm{ng} / \mathrm{mL}$, a PSA doubling time of 16 months or less, postcryotherapy PSA nadir above $0.1 \mathrm{ng} / \mathrm{mL}$, clinical stage higher than T3, and biopsy Gleason score of the local recurrence higher than 9 [14, 17-20]. Recently, a large multi-institutional study comprising a pool of 450 salvage patients was published by Spiess and colleagues [21] with the intent to create a pretreatment nomogram. At a median follow-up of 3.4 years, the overall rate of biochemical failure was $66 \%$ (PSA $>0.5 \mathrm{ng} / \mathrm{mL}$ ). Significant multivariate predictors of biochemical failure included serum PSA at diagnosis (1 unit increases in the log$\log$ of the serum PSA [OR 3.8]) and Gleason score at diagnosis (Gleason $\geq 8$ [OR 2.9]).

Biochemical failure rates vary not only according to the definition of failure, but also due to the generation of the cryounit, cycling parameters, clinicopathologic characteristics, and length of follow-up. Across most definitions, biochemical failure-free rates vary from $59 \%$ to $74 \%[12 \bullet]$. Table 1 lists a more specific breakdown of oncologic variables and outcomes in recent series. Several papers have reported on long-term disease-specific survival rates. Bahn et al. [22] reported a $59 \%$ to $69 \%(0.5 \mathrm{ng} / \mathrm{mL}$ definition and $1.0 \mathrm{ng} / \mathrm{mL}$, respectively) biochemical disease-free survival over a median follow-up of 6.9 years. Most failures occurred before 3 years, and late failures beyond 48 months were not observed during the study follow-up. Cheetham and colleagues [23] provided survival data for 51 patients who underwent salvage treatment, reporting prostate cancer death in 8 of $51(15.7 \%)$ patients at a median time of 6.8 years after cryoablation. Williams et al. [16•] reported an $87 \%$ 10-year overall survival rate in men undergoing salvage cryoablation; the disease-specific survival and disease-free survival were $64 \%$ and $39 \%$, respectively. In terms of prognostic factors, they found a PSA nadir above $1.0 \mathrm{ng} / \mathrm{mL}$ was significantly associated with poor prognosis.

A major concern with the use of less aggressive tissuepreserving (eg, urethra) strategies is incomplete treatment of cancerous foci in remnant locations. A report that may temper enthusiasm for salvage ablative therapy was published from Huang and colleagues [24], who documented the distribution of cancerous foci on whole mount sectioning after salvage radical prostatectomy. Among 46 patients with a median post-RT PSA of $4.3(94 \% \leq \mathrm{cT} 2$, and $68 \%$ Gleason 6 to 7), extracapsular extension was present in $43 \%$ and seminal vesicle invasion (SVI) in $28 \%$. Periurethral tumors were noted in $67 \%$ of cases, with $7 \%$ of tumors in direct contact with the urethra. An additional $17.4 \%$ of tumors were located within $2 \mathrm{~mm}$ of the urethra. Geographically, the apex contained cancer in $93 \%$ of cases. This information is sobering for the cryosurgeon who relies on the thermoprotection of the urethral warming catheter and apical thermocouples to balance the challenge of complete treatment of the apex with the risk of cryoinjury to the urethral sphincter. One must keep in mind that critical temperatures of $-20^{\circ} \mathrm{C}$ 


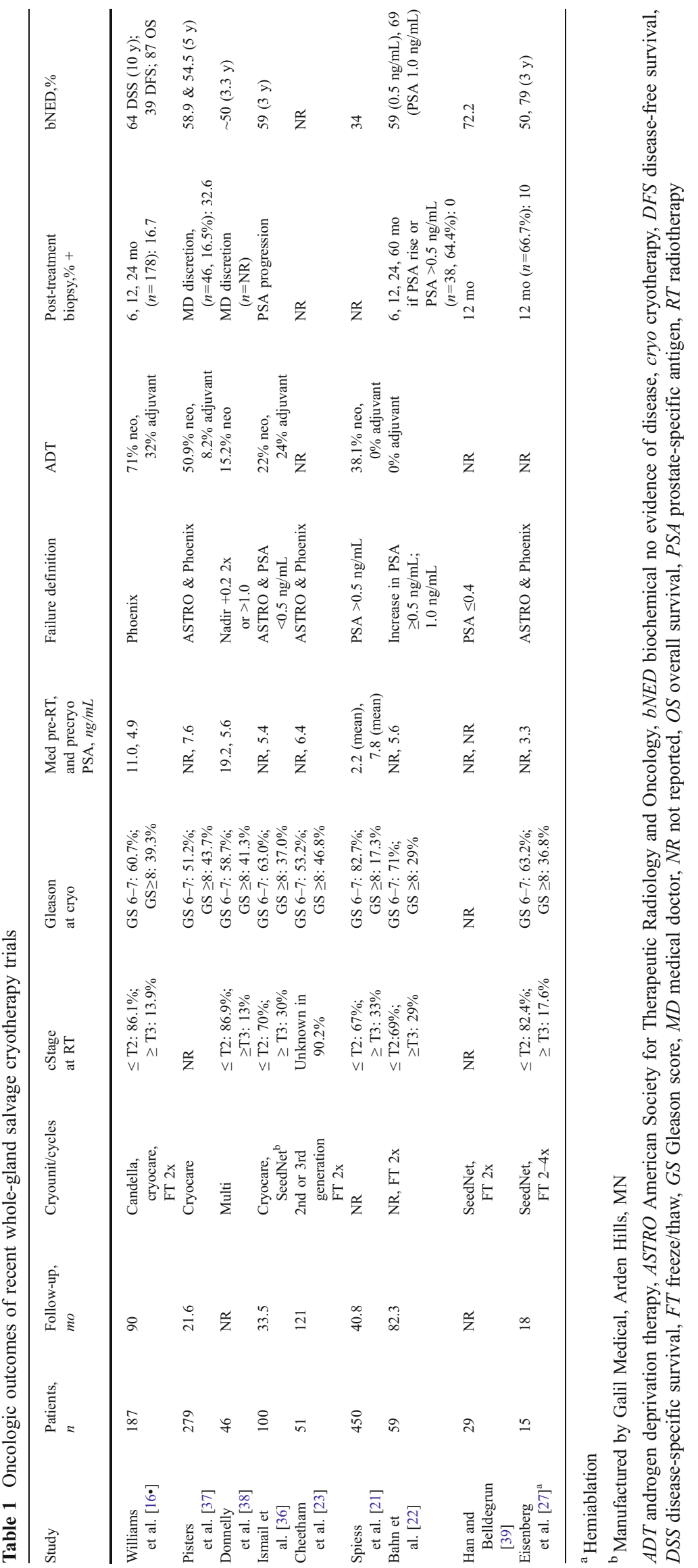


are not achieved at the perimeter of the iceball [11]. If failure after salvage prostatectomy is chiefly due to micrometastatic disease, the higher failure rates after salvage ablative therapy must also include SVI and residual foci of cancer outside the iceball's "kill zone." In addition, there is some evidence that hormone-resistant prostate cancer cells are more resistant to cryo-induced cell death, questioning the frequent use of prolonged androgen deprivation therapy before cryotherapy [25]. Multiparametric endorectal magnetic resonance imaging (MRI), ultrasound technology, and molecular imaging continue to improve their discriminatory power to map the precise anatomic location of tumors. Concurrently, biopsy technique is becoming less user-dependent with technologies including MRI/ultrasound fusion [26•] and the Artemis device (Eigen Corporation, Grass Valley, CA). The net result of these technological advancements is enhanced patient selection and increased accuracy for salvage ablative treatment.

While whole-gland salvage cryoablation is the standard treatment template, some centers are exploring the use of partial salvage cryoablation (ie, hemiablation, focal ablation) in an effort to minimize complication rates, [27]. Eisenberg and Shinohara achieved 3-year biochemical recurrence-free survival rates of $89 \%$ (ASTRO) and 79\% (Phoenix) for patients undergoing salvage hemi-ablation. On 12-month follow-up biopsy, 1 of 10 patients had residual disease, notably in the contralateral lobe and seminal vesicle. Extreme caution must be exercised given the presence of occult multifocality. In addition, in this series, three patients went on to develop metastatic disease. Although clearly investigational at this time, in highly selected patients (eg, unilateral, low-volume, low-grade disease) unwilling to undergo more definitive treatment, focal salvage ablation may be a guarded option.

\section{Functional Outcomes}

Unfortunately, most cryoablation studies lump functional outcomes along with complications rather than reporting objective validated instrument-based health-related quality of life (HRQOL) information obtained at baseline and long-term follow-up. Ideally, urologists should establish baseline, short-term, and long-term urinary, sexual, and bowel function utilizing patient-reported questionnaires such as the International Prostate Symptom Score and Sexual Health Inventory for Men. However, in practice, these instruments are underutilized and data are sparse. Abdelhady and colleagues [28•] published, in abstract form, a HRQOL survey based on the Expanded Prostate Cancer Index Composite questionnaire after salvage cryosurgery in 155 men. While no baseline information was reported, among the $68 \%$ of men who responded, the average post-treatment AUA symptom score was 11.1 (moderate symptoms), with adequate satisfaction among respondents. In a prospective study of patients undergoing salvage cryoablation, Robinson and colleagues [29] followed men at regular intervals to 24 months after treatment. Based on the European Organization for Research and Treatment of Cancer QLQ-C30 and UCLA (University of California, Los Angeles) Prostate Cancer Index instruments, both sexual and urinary bother significantly increased between baseline (35.6\% and $0 \%$, respectively) and 24-month follow-up (51.9\% and 29\%, respectively).

\section{Urinary Function}

Although now over a decade old, in perhaps the largest HRQOL study among salvage cryotherapy patients, $72 \%$ of men reported some degree of dribbling or leakage at a mean follow-up of 16.7 months [30]. In addition, $66 \%$ of men reported moderate to severe voiding symptoms. Nguyen and colleagues [13] found a weighted average incontinence rate of $36 \%$ among salvage studies performed between 1990 and 2002; however, definitions of incontinence were heterogeneous and not all series included the use of urethral warming catheters. The weighted average for the more up-to-date series listed in Table 2 is about $21.7 \%$ across multiple definitions of incontinence (eg, any leakage, $\geq 1$ pad) and time frames.

Levy [31] recently reported a correlation between thermocouple temperatures and voiding function after prostate cryoablation. In this retrospective series of 58 patients, 10 patients had a history of prior RT. Overall, $37.9 \%$ of patients had "altered voiding function" consisting of a significant change in voiding pattern (eg, urgency, frequency, postvoid residual). Among patients with a mean external sphincter temperature less than $23^{\circ} \mathrm{C}, 55 \%$ suffered from altered voiding compared with $25 \%$ of patients who achieved nadir sphincteric temperatures above this threshold. However, on multivariate analysis, an external sphincter temperature of $23^{\circ} \mathrm{C}$ or less was significantly associated with altered voiding function (OR 6.26; $P=0.012$ ). Among salvage patients, $50 \%$ experienced abnormal voiding, although this was not statistically significant due to small sample size.

Patients undergoing salvage cryoablation tend to have a significantly higher complication rate compared with men undergoing primary treatment due to the retreatment of irradiated, poorly vascularized, anatomically altered tissue [30, 32, 33]. Yin et al. [34] utilized SEER (Surveillance, Epidemiology, and End Results)-Medicare-linked data among patients who had undergone salvage cryotherapy, reporting a $30 \%$ prevalence of an incontinence diagnosis 


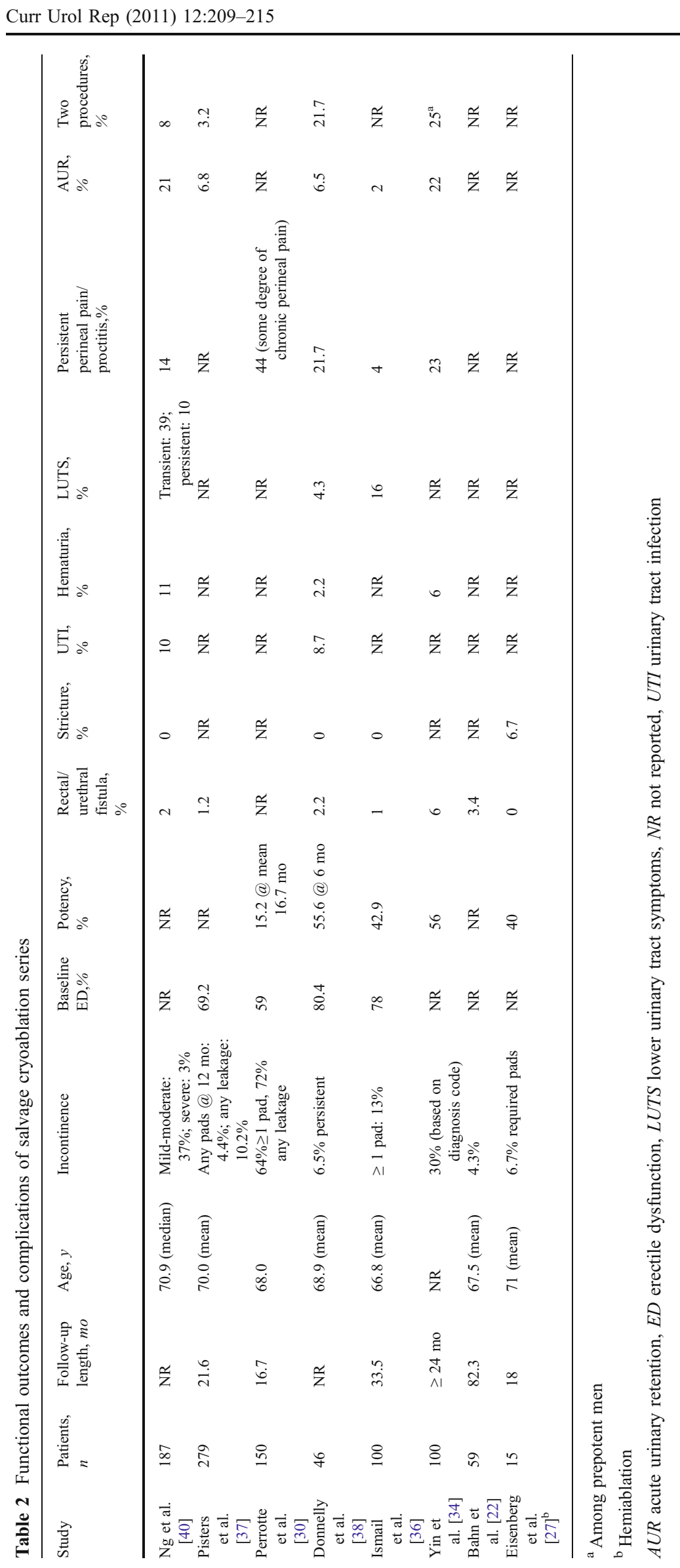

包 Springer 
compared with $25.0 \%$ of men undergoing primary cryotherapy. In another series that included primary and salvage groups, Anastasiadis and colleagues [35] reported incontinence rates of $5.9 \%$ and $10 \%$, respectively, and erectile dysfunction rates of $86 \%$ and $90 \%$, respectively. Thus, while the salvage patients generally tend to have higher complication rates and worse functional outcomes, the magnitude of the difference is much less in modern series.

\section{Erectile Function}

Baseline erectile dysfunction rates are high after RT at study entry for most cryoablation series, especially in light of possible hormonal use, ranging from about $60 \%$ to $80 \%$ (Table 2). In addition, the use of phosphodiesterase-5 inhibitors and injection therapy often are unclear in many reports. However, some general trends can be extracted from the literature. Utilizing validated questionnaires, Perotte and colleagues [30] found, among the $41 \%$ of prepotent men before salvage cryotherapy, only $15.2 \%$ were able to achieve penetration after treatment; an additional $23.9 \%$ of men had partial erections. Ismail et al. [36] found 6 of 14 (42.9\%) prepotent men retained their baseline function. Yin et al. [34] reported a $44 \%$ prevalence of an erectile dysfunction diagnosis compared with $38.2 \%$ of men undergoing primary cryotherapy. Whether or not the continuous administration of phosphodiesterase-5 inhibitors improves erectile function following salvage cryoablation awaits prospective randomized data.

\section{Complications}

Historically, with first-generation liquid nitrogen-based systems, lack of urethral warmers, and thermocouples, the most feared complications such as rectal fistula, urethral sloughing, and urinary incontinence were encountered at an unacceptable rate. Today, with third-generation cryounits, smaller probes with variable isotherm contours, advanced imaging, multitemperature thermocouples to precisely monitor temperatures near critical structures, and urethral warmers, complication rates have improved dramatically. In the salvage setting, regardless of the treatment modality, the observed complication rates are higher than for primary treatment $[12 \cdot, 13,17,30]$. However, overall contemporary complication rates for salvage cryoablation have trended down to reasonable levels. Particularly for the older comorbid patient who is not an ideal candidate for mainstay salvage prostatectomy, cryoablation may be an acceptable option. The most prevalent complications are listed in Table 2.

\section{Conclusions}

Tremendous technological inroads have led to the firm establishment of salvage cryosurgery as a viable treatment option with curative intent for radio-recurrent prostate cancer. Durable biochemical relapse-free rates range from $34 \%$ to $68 \%$ depending on the definition. Complication rates have trended down with advances in technique and technology. Standardized, protocol-based, clinical trials are needed.

Disclosures Dr. David Finley: none. Dr. Arie Belldegrun has served as a consultant for Galil Medical.

Open Access This article is distributed under the terms of the Creative Commons Attribution Noncommercial License which permits any noncommercial use, distribution, and reproduction in any medium, provided the original author(s) and source are credited.

\section{References}

Papers of particular interest, published recently, have been highlighted as:

- Of importance

1. Mettlin CJ, Murphy GP, Rosenthal DS, et al. The National Cancer Data Base report on prostate carcinoma after the peak in incidence rates in the U.S. The American College of Surgeons Commission on Cancer and the American Cancer Society. Cancer. 1998;83:1679-84.

2. Mettlin CJ, Murphy GP, McDonald CJ, et al. The National Cancer Data Base Report on increased use of brachytherapy for the treatment of patients with prostate carcinoma in the U.S. Cancer. 1999;86:1877-82.

3. Shipley WU, Thames HD, Sandler HM, et al. Radiation therapy for clinically localized prostate cancer: a multi-institutional pooled analysis. JAMA. 1999;281:1598-604.

4. D'Amico AV, Chen MH, Renshaw AA, Loffredo B, Kantoff PW. Risk of prostate cancer recurrence in men treated with radiation alone or in conjunction with combined or less than combined androgen suppression therapy. J Clin Oncol. 2008;26:297983.

5. Suzuki N, Shimbo M, Amiya Y, et al. Outcome of patients with localized prostate cancer treated by radiotherapy after confirming the absence of lymph node invasion. Jpn J Clin Oncol. 2010;40:652-7.

6. Touma NJ, Izawa JI, Chin JL. Current status of local salvage therapies following radiation failure for prostate cancer. J Urol. 2005;173:373-9.

7. Zietman AL, Bae K, Slater JD, et al. Randomized trial comparing conventional-dose with high-dose conformal radiation therapy in early-stage adenocarcinoma of the prostate: long-term results from proton radiation oncology group/American College of radiology 95-09. J Clin Oncol. 2010;28:1106-11.

8. Crook JM, Perry GA, Robertson S, Esche BA. Routine biopsies following radiotherapy for prostate cancer: results for 226 patients. Urology. 1995;45:624-31. 
9. Siddiqui SA, Mynderse LA, Zincke H, et al. Treatment of prostate cancer local recurrence after radical retropubic prostatectomy with 17-gauge interstitial transperineal cryoablation: initial experience. Urology. 2007;70:80-5.

10. Chin JL, Lim D, Abdelhady M. Review of primary and salvage cryoablation for prostate cancer. Cancer Control. 2007;14:231-7.

11. Finley DS, Pouliot F, Miller DR, Belldegrun AS. Primary and salvage cryotherapy for prostate cancer. Urol Clin North Am. 2010;37:67-82.

12. - Babaian RJ, Donnelly B, Bahn D, et al.: AUA Best practice statement on cryosurgery for the treatment of localized prostate cancer. J Urol 2008. 180:1993-2004. This is the American Urological Association consensus statement on the cryosurgery, an evidencebased review of the literature with panel recommendations.

13. Nguyen PL, D'Amico AV, Lee AK, Suh WW. Patient selection, cancer control, and complications after salvage local therapy for postradiation prostate-specific antigen failure: a systematic review of the literature. Cancer. 2007;110:1417-28.

14. Spiess PE, Lee AK, Leibovici D, et al. Presalvage prostate-specific antigen and PSA doubling time as predictors of biochemical failure of salvage cryotherapy in patients with locally recurrent prostate cancer after radiotherapy. Cancer. 2006;107:275-80.

15. Vergunst H, Langenhuijsen JF. Rebuttal from Authors re: J. Stephen Jones. Ten Misconceptions regarding cryotherapy for prostate cancer. Eur Urol. 2009;55:52-5.

16. - Williams A, Martinez C., Chalasani V, Pautler SE, Chin JL. Long term results of salvage cryotherapy for prostate cancer. Presented at the 11th Annual Meeting of the Society of Urologic Oncology, Bethesda, Maryland; Dec 8-10, 2010. This is one of the largest salvage cryoablation series and longest series to date

17. Chin JL, Pautler SE, Mouraviev V, et al. Results of salvage cryoablation of the prostate after radiation: identifying predictors of treatment failure and complications. J Urol. 2001;165:1937-42.

18. De la Taille A, Benson MC, Bagiella E, et al. Cryoablation for clinically localized prostate cancer using an argon-based system: complication rates and biochemical recurrence. BJU Int. 2000;85:281-6.

19. Izawa JI, Madsen LT, Scott SM, et al. Salvage cryotherapy for recurrent prostate cancer after radiotherapy: variables affecting patient outcome. J Clin Oncol. 2002;20:2664-71.

20. Pisters LL, Perrotte P, Scott SM, et al. Patient selection for salvage cryotherapy for locally recurrent prostate cancer after radiation therapy. J Clin Oncol. 1999;17:2514-20.

21. Spiess PE, Katz AE, Chin JL, et al. A pretreatment nomogram predicting biochemical failure after salvage cryotherapy for locally recurrent prostate cancer. BJU Int. 2009;106:194-8.

22. Bahn DK, Lee F, Silverman P, et al. Salvage cryosurgery for recurrent prostate cancer after radiation therapy: a seven-year follow-up. Clin Prostate Cancer. 2003;2:111-4.

23. Cheetham P, Truesdale M, Chaudhury S, et al. Long-term cancerspecific and overall survival for men followed more than 10 years after primary and salvage cryoablation of the prostate. J Endo. 2010;24:1123-9.

24. Huang WC, Kuroiwa K, Serio AM, et al. The anatomical and pathological characteristics of irradiated prostate cancers may influence the oncological efficacy of salvage ablative therapies. J Urol. 2007;177:1324-9.
25. Klossner DP, Baust JM, VanBuskirk RG, Gage AA, Baust JG. Cryoablative response of prostate cancer cells is influenced by androgen receptor expression. BJU Int. 2008;101:1310-6.

26. - Rastinehad A, Benjamin C, Chung P, et al.: Cancer detection rates on $\mathrm{MR} /$ Ultrasound fused image guided prostate biopsies directly correlates with multi-parametric MRI. Presented at the 11th Annual Meeting of the Society of Urologic Oncology, Bethesda, Maryland; Dec 8-10, 2010. This article provides one of several examples of rapidly improving biopsy technique using fusion of magnetic resonance and ultrasound.

27. Eisenberg ML, Shinohara K. Partial salvage cryoablation of the prostate for recurrent prostate cancer after radiotherapy failure. Urology. 2008;72:1315-8.

28. - Abdelhady M, Abusamra A, Elmaadawi A, et al.: Health related quality of life (HRQOL) outcome after salvage cryosurgery of the prostate: comparison with outcome after primary radiotherapy. $\mathrm{J}$ Urol suppl 2007. 177:3. This is one of few HRQOL studies on salvage cryoablation using validated instruments.

29. Robinson JW, Donnelly BJ, Coupland K, et al. Quality of life 2 years after salvage cryosurgery for the treatment of local recurrence of prostate cancer after radiotherapy. Urol Oncol. 2006;24:472-86.

30. Perrotte P, Litwin M, McGuire EJ, et al. Quality of life after salvage cryotherapy: the impact of treatment parameters. J Urol. 1999; 162:398-402.

31. Levy DA. Correlation of thermocouple data with voiding function after prostate cryoablation. Urology. 2010;75:482-7.

32. De la Taille A, Hayek O, Benson MC, et al. Salvage cryotherapy for recurrent prostate cancer after radiation treatment: the Columbia experience. Urology. 2000;55:79-84.

33. Long JP, Fallick ML, LaRock DR, Rand W. Preliminary outcomes following cryosurgical ablation of the prostate in patients with clinically localized prostate carcinoma. J Urol. 1998;159:477-84.

34. Yin L, Choi WW, Gu X, et al.: Complications of primary vs salvage cryotherapy for prostate cancer. Presented at the American Urologic Association Meeting. San Francisco, California; May 29-June 3, 2010, Abstract \#1066.

35. Anastasiadis AG, Sachdev R, Salomon L, et al. Comparison of health-related quality of life and prostate-associated symptoms after primary and salvage cryotherapy for prostate cancer. J Cancer Res Clin Oncol. 2003;129:676-82.

36. Ismail M, Ahmed S, Kastner C, Davies J. Salvage cryotherapy for recurrent prostate cancer after radiation failure: a prospective case series of the first 100 patients. BJU Int. 2007;100:760-4.

37. Pisters LL, Rewcastle JC, Donnelly BJ, et al. Salvage prostate cryoablation: initial results from the cryo on-line data registry. $\mathrm{J}$ Urol. 2008;180:559-64.

38. Donnelly BJ, Saliken JC, Ernst DS, et al. Role of transrectal ultrasound guided salvage cryosurgery for recurrent prostate carcinoma after radiotherapy. Prostate Cancer Prostatic Dis. 2005;8:235-42.

39. Han KR, Belldegrun AS. Third-generation cryosurgery for primary and recurrent prostate cancer. BJUI. 2004;93:14-8.

40. Ng CK, Moussa M, Downey DB, Chin JL. Salvage cryoablation of the prostate: followup and analysis of predictive factors for outcome. J Urol. 2007;178:1253-7. 